Erratum

\title{
Correction: MiR-940 inhibits TGF- $\beta$-induced epithelial-mesenchymal transition and cell invasion by targeting Snail in non-small cell lung cancer
}

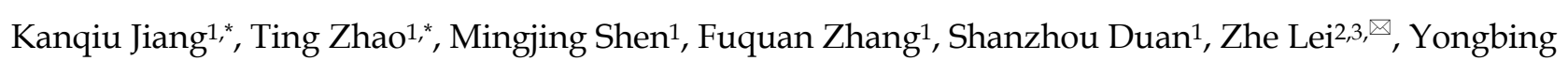
Chen $^{1,} \bowtie$

1. Department of Thoracic and Cardiovascular Surgery, The Second Affiliated Hospital of Soochow University, Medical College of Soochow University, Suzhou 215004, China

2. Soochow University Laboratory of Cancer Molecular Genetics, Medical College of Soochow University, Suzhou 215123, China

3. Department of Genetics, School of Biology and Basic Medical Science, Medical College of Soochow University, Suzhou, Jiangsu, 215123, China

* These authors contributed equally to this work.

$\triangle$ Corresponding authors: Zhe Lei, Soochow University Laboratory of Cancer Molecular Genetics, Medical College of Soochow University, 199 Ren'ai Road, Sino-Singapore Industrial Park, Suzhou 215123, China. E-mail: leizhe@suda.edu.cn, and Yongbing Chen, Department of Thoracic and Cardiovascular Surgery, The Second Affiliated Hospital of Soochow University, Medical College of Soochow University, 1055 Sanxiang Street, Suzhou 215004, China. E-mail: chentongt@sina.com

(C) The author(s). This is an open access article distributed under the terms of the Creative Commons Attribution License (https://creativecommons.org/licenses/by/4.0/). See http://ivyspring.com/terms for full terms and conditions.

Published: 2020.06.11

Corrected article: J Cancer 2019; 10(12):2735-2744. doi:10.7150/jca.31800.

In the initially published version of this article, the representative images of the invasion test of A549 cells overexpressing miR-940 with or without TGF- $\beta 1$ stimulation in Figure 3C are wrong. The correct Figure 3C is as follows: 
C
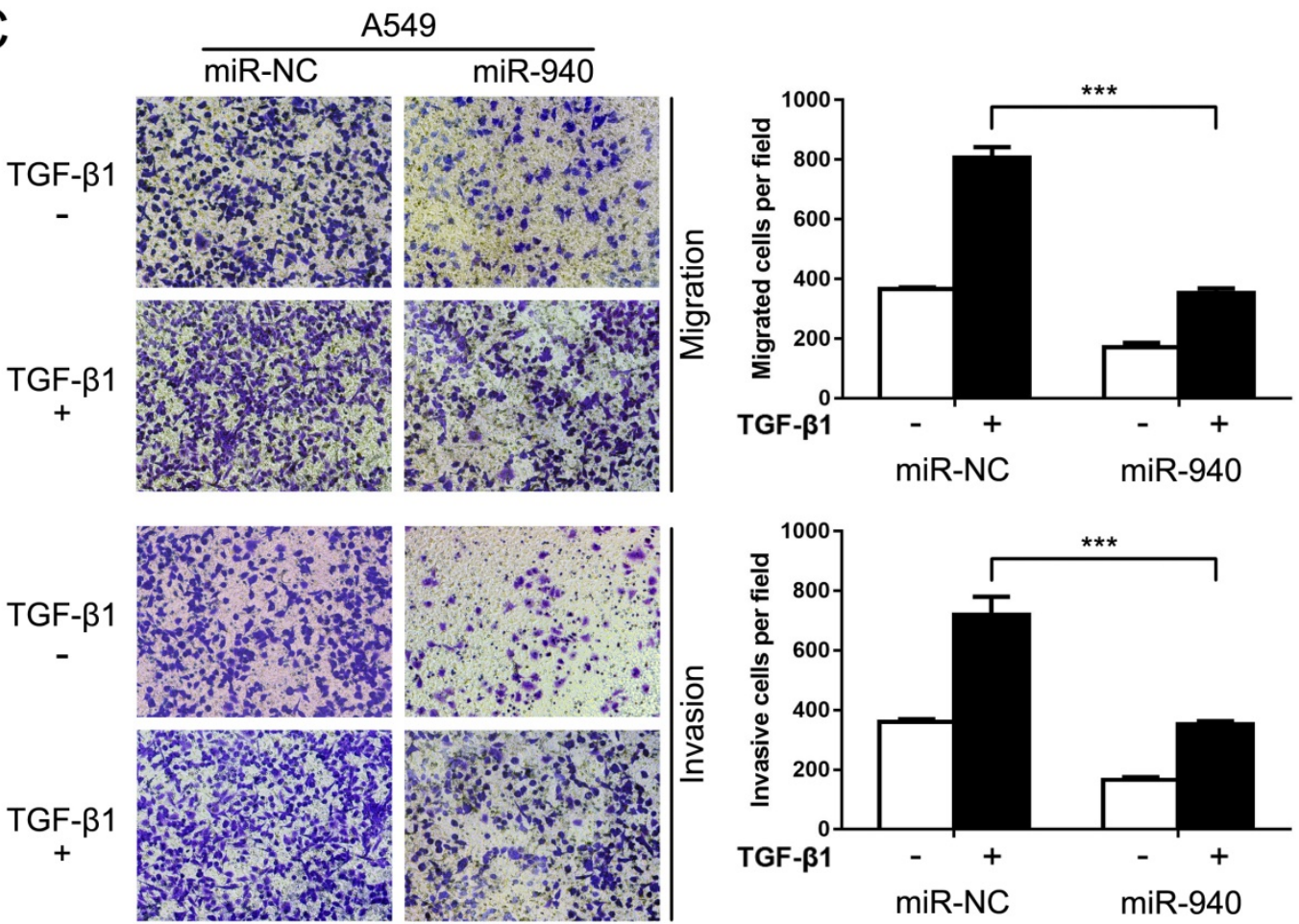

Figure 3. (C) Transwell assays for A549 cells transfected with miR-NC or miR-940 mimics in the absence or presence of TGF- $\beta 1$. Migrated and invaded cells were stained and counted in at least three microscopic fields (magnification $\times 100$ ).

The correction made in this erratum does not affect the counting results and original conclusions. The authors apologize for any inconvenience or misunderstanding that this error may have caused.

\section{References}

1. Jiang K, Zhao T, Shen M, Zhang F, Duan S, Lei Z, Chen Y. MiR-940 inhibits TGF- $\beta$-induced epithelial-mesenchymal transition and cell invasion by targeting Snail in non-small cell lung cancer. J Cancer 2019; 10(12):2735-2744. doi:10.7150/jca.31800. 